\title{
Effect of the two-phase hybrid mode of effervescent atomizer on the atomization characteristics
}

https://doi.org/10.1515/phys-2019-0101

Received Jul 08, 2019; accepted Nov 08, 2019

\begin{abstract}
In this paper, the atomization characteristics of an effervescent atomizer were investigated. The velocity, Sauter Mean Diameter (SMD) and atomization cone angle of the droplets were measured using the Phase Doppler Analyzer (PDA) to discuss the effect of different design parameters. The results showed that the atomization was unstable at a small Gas-Liquid Rate (GLR) while the atomization proved gradually by increasing the GLR. The optimal atomization region was at a $G L R=0.1$. In the atomization process, there existed a typical velocity distribution for the swirl atomizer. The design parameters of atomizer provided a great influence on the Sauter Mean Diameter $(S M D)$ and atomization cone angle. The experiment results showed that some droplets had negative velocities.
\end{abstract}

Keywords: effervescent atomization, velocity distribution, Sauter Mean Diameter (SMD), swirl atomizer

PACS: $47.60 \mathrm{kz}, 47.27 . \mathrm{wg}$, 47.55D-

\section{Introduction}

The gas-assisted atomization is widely used in the atomization process of liquid fuels. The effervescent atomization provides several advantages, such as high atomization quality, low pressure, lower energy consumption, sim-

\footnotetext{
${ }^{\star}$ Corresponding Author: Runze Duan: School of energy and environmental engineering, Hebei University of Technology, Tianjin, 300401, China; Email: duanrunze@hebut.edu.cn; Tel.: +8602260438208

*Corresponding Author: Yan Zhang: School of software, Nanyang Institute of Technology, Nanyang, 473004, China; Email: 1468969367@qq.com

Liansheng Liu, Na Pei, Ruolin Zhao, Liang Tian, Menghan Li, Xiaoyu Zhang: School of energy and environmental engineering, Hebei University of Technology, Tianjin, 300401, China
}

Ә Open Access. (c) 2019 L. Liu et al., published by De Gruyter. License ple and reliable system and so on. At present, the effervescent atomization has a wide range of applications in the liquid fuel combustion, spray cooling, spray irrigation, water mist for fire suppression, etc.

The process of the effervescent atomization was firstly investigated in the 1980s [1]. By means of injecting gas into the liquid, the bubble flow formed in the internalmixing chamber of the atomizer and the effervescent atomization was achieved through the liquid and gas interaction. When the liquid and gas external forces, such as the shear force were greater than the fluid surface tension and viscous forces, the liquid was stretched and broke into small droplets. When the gas and droplets continued to interact, small droplets further broke into smaller liquid particles, and the atomization process was achieved.

The effect of the atomizer internal geometry, including the gas-to-liquid rate and injection pressure on the nozzle atomization characteristics had been studied extensively by Sovani et al. [2]. It was found that the gas-liquid rate needed for effervescent atomization was lower compared to other kinds of twin-fluid atomization. Three kinds of multi-hole effervescent atomizers with different configurations were investigated by Li et al. [3]. It was concluded that the multi-hole effervescent atomizers achieved good atomization with a uniform liquid flux distribution. The high-viscosity Newtonian liquid flow in the near-atomizer spray configuration was investigated by Buckner and Sojka $[4,5]$. They investigated the bubble expansion and liquid-shattering mechanisms. Roesler and Lefebvre $[6,7]$ and Santangelo and Sojka [8] observed the same phenomenon. Konstantinov [9] thought that the effervescent atomizer can operate at the lower pressure and generate small mean droplets diameter. Jedelsky and Jicha [10] concluded that the explosions of gas bubbles enhanced the instability in the spray process. Several researchers [11-14] have studied the near-atomizer structure of the spray produced by a ligament-controlled effervescent atomizer.

All the investigations above focused on the mechanism of the effervescent atomization. However, the atomization quality was not mentioned and elaborated. The 
mean droplets size at the lowest reported injection pressure $(34.5 \mathrm{kPa})$ was measured by Wang et al. [15]. The results showed that the spray mean droplets size was reduced by increasing the injection pressure, while a higher effect was pronounced at lower injection pressures. The effect of the pressure on the behavior of droplets was investigated by Liu et al. [16], Jedelsky et al. [17] and Ge et al. [18]. It was concluded that the SMD decreased gradually with the increase in the pressure, and remained constant when the pressure was higher than 20bar. Jedelsky et al. [17] found that the atomizer structure had a great effect on the atomization quality. Several researchers [19-23] had examined the effect of GLR on the mean droplets size distribution and concluded that the latter remained fairly constant as the GLR changed.

The main purpose of this paper was to investigate the velocity and $S M D$ radial droplets distributions within two different atomizers.

\section{Experimental system and atomizer design}

The Experimental system was illustrated in Figure 1. High pressure gas and liquid provided by the air compressor and mixed in the atomizer and then flowed downstream to the exit orifice. The liquid and gas flow rates were measured by the mass flow meter and volume flow meter, respectively. The velocity and size of the droplets were measured by the Phase Doppler Analyzer (PDA).

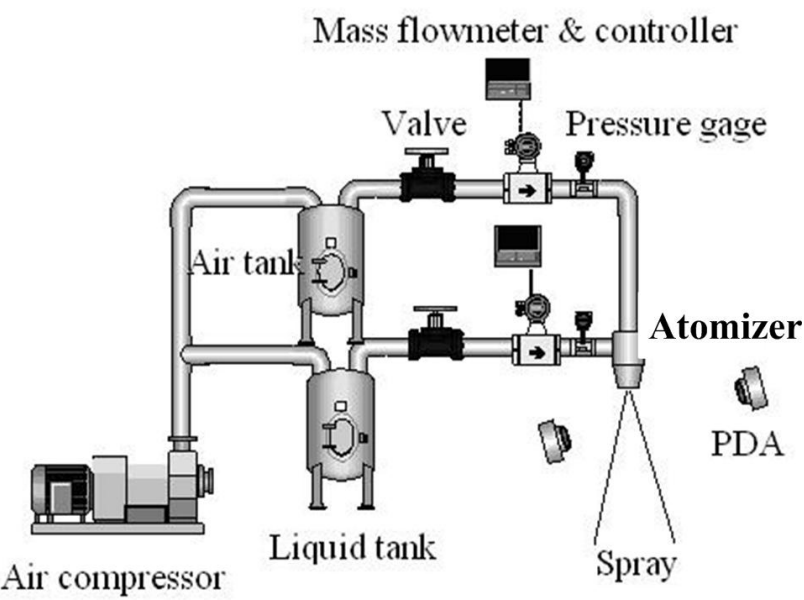

Figure 1: Experimental system

Before entering the atomizer, the pressure of the liquid and gas were increased to 0.3MPa. The detailed dimen-
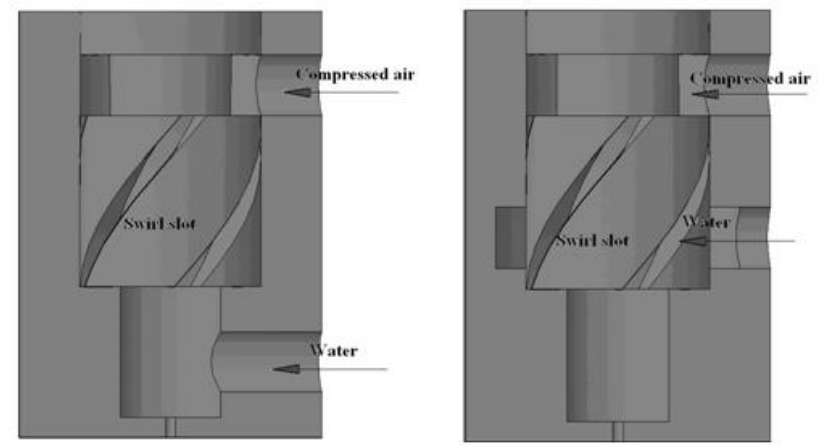

Figure 2: The structure of the atomizers for (a) Swirl atomizer A and (b) Swirl atomizer B

sions of the atomizers were shown in Figure 2. Two atomizers were named as swirl atomizer A and swirl atomizer B, respectively. The diameter of the exit orifice was $D=1.0 \mathrm{~mm}$, identical to that of the atomizer $D_{c}$. In the swirl atomizer A, the gas passing through the swirl slot was mixed with the liquid for atomization. In the swirl atomizer B, the mixing process occurred before the atomization. The gas and liquid fully mixed inside the atomizer were sprayed out through the exit orifice.

\section{Results and discussion}

\subsection{Atomization characteristics in the two-phase hybrid atomizer}

The relationship between the liquid mass flow rate and the gas-liquid rate $(G L R)$ are described in Figure 3. The gas and liquid pressure ranged from 0.26 to $0.32 \mathrm{MPa}$. It can be

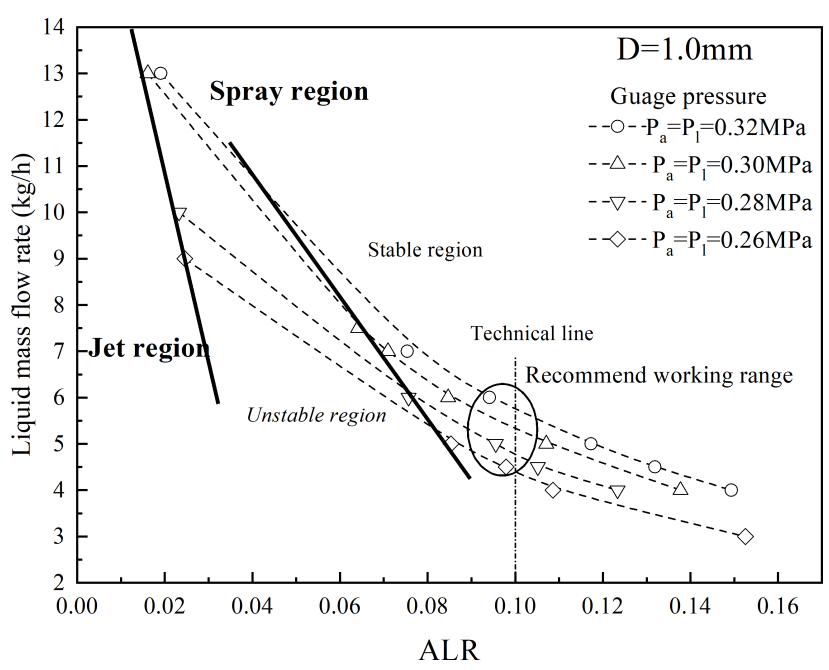

Figure 3: Effect of the ALR and pressure on the liquid mass flow rate 

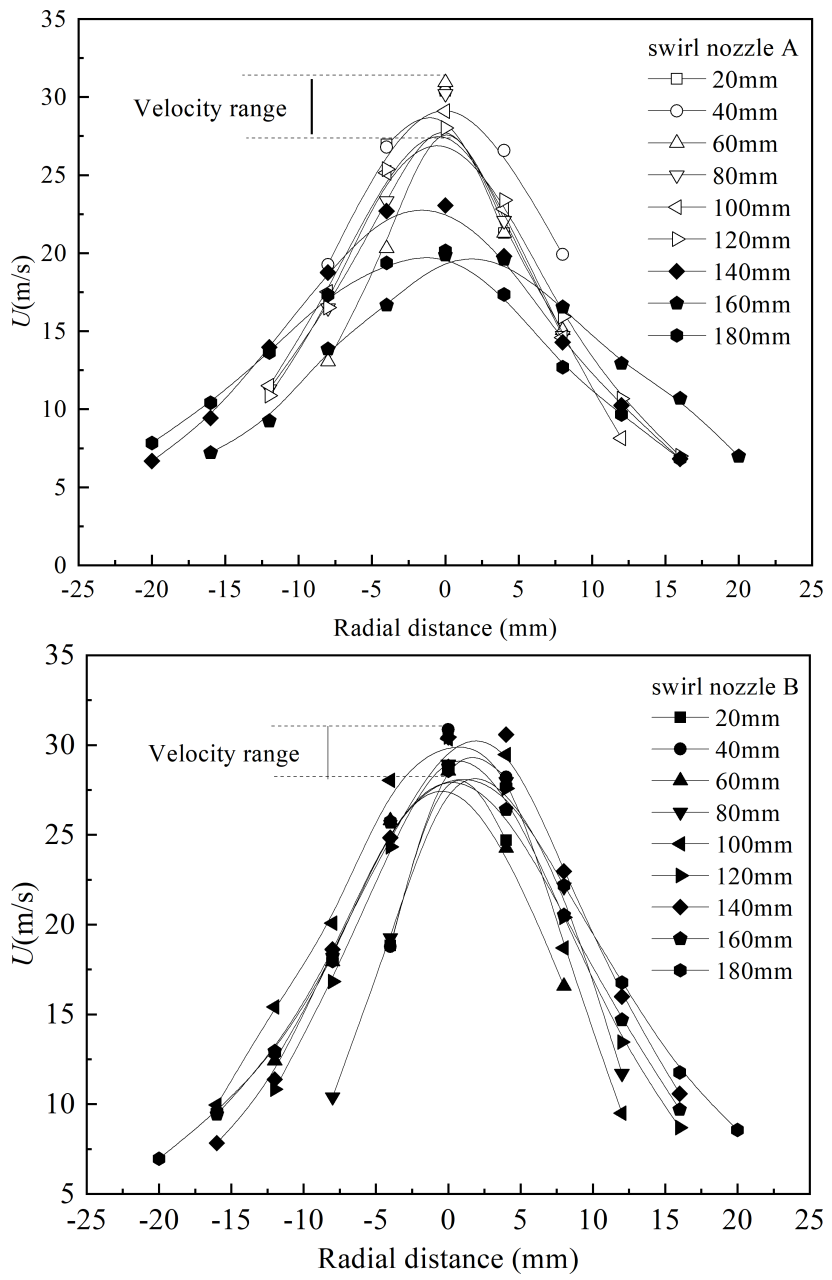

Figure 4: Velocity $\mathrm{U}$ of swirl atomizer $\mathrm{A}$ in radial distribution

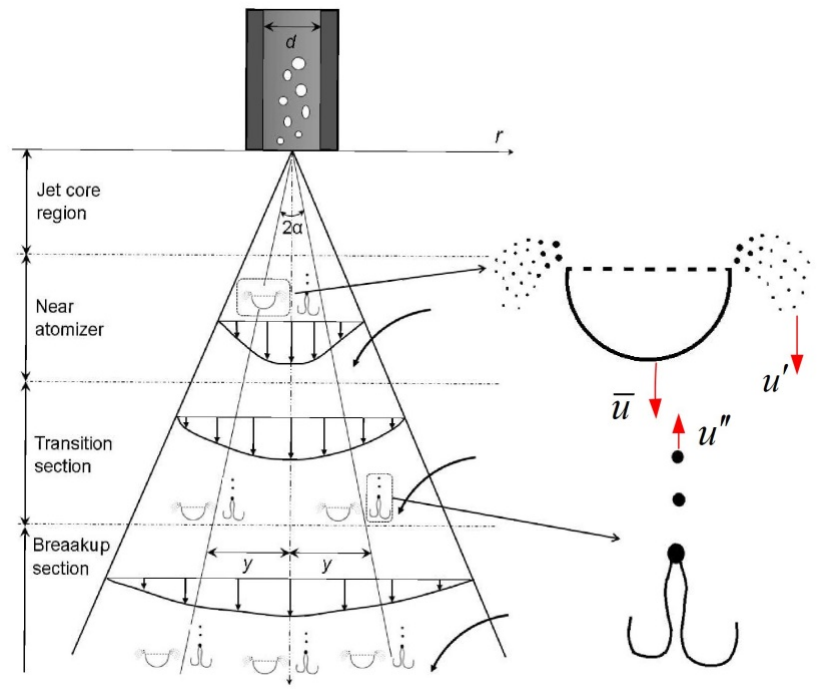

Figure 5: SMD radial distribution in different section downstream of swirl atomizer $A$

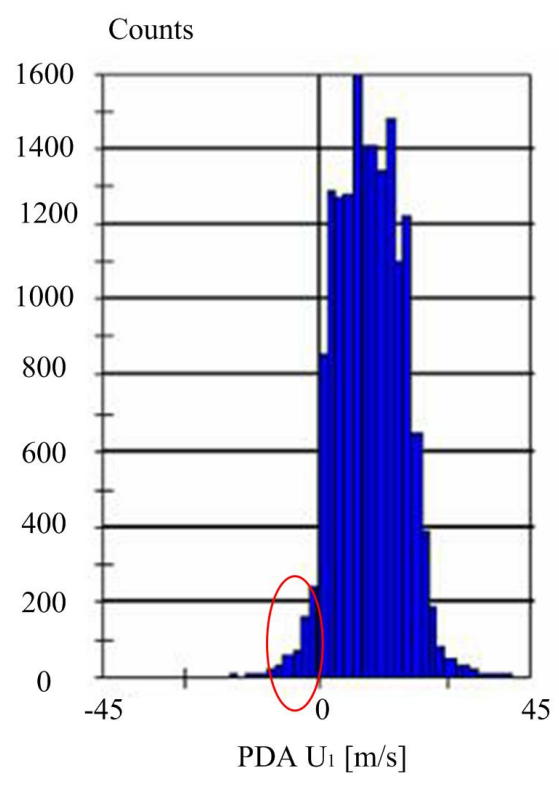

Figure 6: Jet process of the two-phase hybrid atomizer

seen that the liquid mass flow rate decreased by increasing the GLR. In terms of physics, when the GLR was small, the amount of the liquid was much higher than that of the gas. As the liquid sprayed into the stationary atmosphere environment, the restriction of the atomizer wall on the liquid suddenly disappeared. Due to the interaction of the gas and liquid, the atomization process was unstable in the gas-liquid boundary layer. By increasing the $G L R$, the atomization became gradually stable. The optimal atomization region was marked by the circle in the Figure 3, while further increase in the GLR may gradually deteriorate the spray effect.

Also, the effect of the pressure on the liquid mass flow rate is shown in Figure 3. At a constant GLR, the liquid mass flow rate increased with the increase in the pressure. The physical mechanisms were explained as follows: with the increase in the pressure, the expansion work, the velocities of the atomization, and the liquid mass flow rate increased. Consequently, the energy consumption also increased.

\subsection{Velocity distribution of swirl atomizers}

Figure 4 shows the radial velocity distribution of two swirl atomizers (A and $\mathrm{B})$. The gas and liquid pressures were set to be $P_{\alpha}=0.3 \mathrm{MPa}(\alpha=1,2$ represented the liquid or gas phase, respectively.). The gas-liquid rate was set to be $G L R=0.1$. The distance from the discharge orifice $(L)$ was varied from $(20 \mathrm{~mm}$ to180mm). For both swirl atomizers (A and $\mathrm{B})$, the radial velocity distribution were symmetrical. 


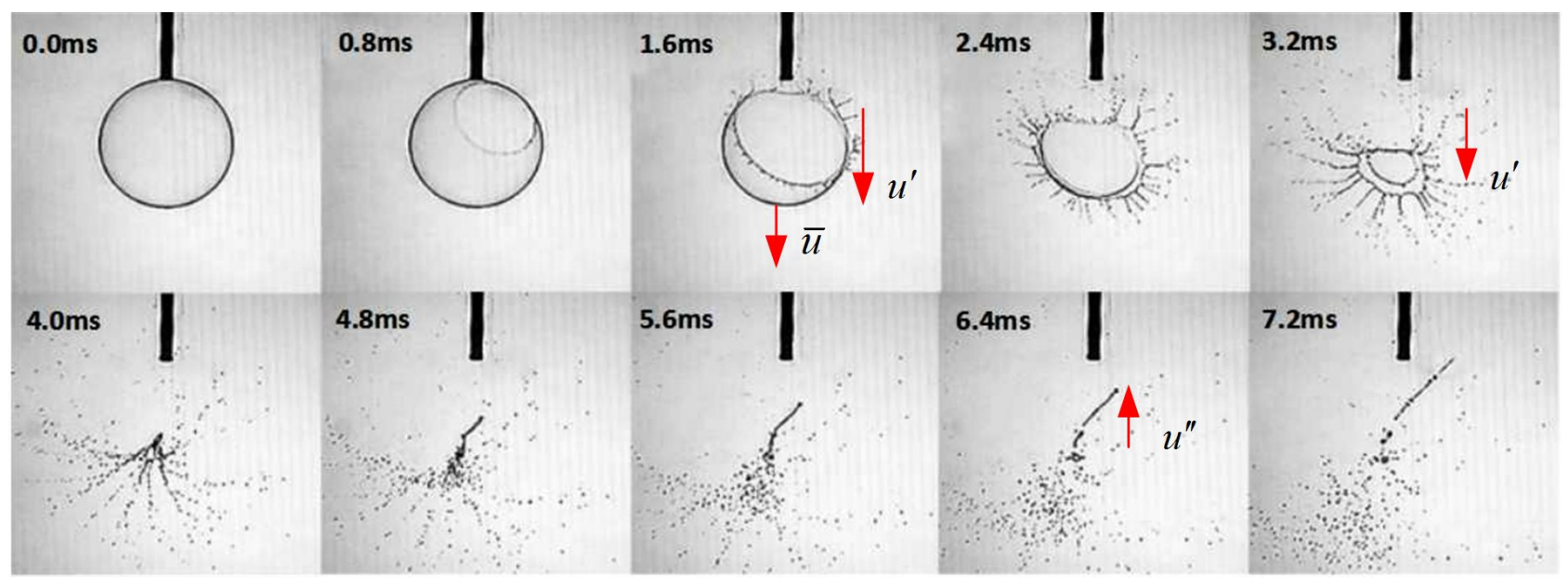

Figure 7: Bubble bursting process

The droplets velocities decreased along the radial direction, and the maximum values were obtained at the discharge orifice centre. The droplets velocities remained constant at the jet core region $(L=10 \mathrm{~mm})$, as shown in Figure 5 . The droplets velocities decreased gradually with the distance from the discharge orifice increase from $140 \mathrm{~mm}$ to $180 \mathrm{~mm}$, as shown in Figure 4. However, when the distance from the discharge orifice ranged from $20 \mathrm{~mm}$ to $120 \mathrm{~mm}$, the variation range of the droplets velocities was relatively small. This phenomenon was different from that occurring inside the conventional atomizers. The physical mechanisms were explained as follows: Many small bubbles were formed in the atomization process, as shown in Figure 5 , which were compressed inside the atomizer. The bubbles erupting from the atomizer would suddenly expand. In the bubble expansion process, the surface tension of the bubble decreased with the increase in the bubble diameter. The bubbles deformed under the aerodynamic force.

Compared to the swirl atomizer A, the radial velocity distribution of droplets at different distances from the discharge orifice in atomizer B was more concentrative. However, the atomization cone angle in swirl atomizer $B$ was smaller than that in swirl atomizer A. In terms of physics, more bubbles were produced in the swirl atomizer $B$. The bubble bursting process took place in whole measurement process.

The velocity distribution of the droplets at the distance from the discharge orifice $L=20 \mathrm{~mm}$ was measured by PDA, as shown in Figure 6. It can be seen that some droplets velocities were is displayed as negative. The physical mechanisms were explained as follows: Many small bubbles were formed in the atomization process. With the bubbles injected into the atmosphere environment, their surface evaporated and sediment. The liquid film of the bubbles became very thin, and the initial local perturbation appeared on the surface of the liquid film. However, the occurrence of the local perturbation was stochastic. The maximum local perturbation usually appeared in the upper surface of the bubbles. The young droplets moved along the tangent direction in the bubble bursting process. The rupture velocity of the liquid film was $5 \mathrm{~m} / \mathrm{s}$ and the liquid film appeared to retract. At $4.8 \mathrm{~ms}$, a velocity opposite to the direction of the initial rupture position occurred at the edge of the liquid film. There was a phenomenon similar to the flow focusing, and the jet droplets were formed, as shown in Figure 7. Consequently, some droplets velocities were displayed as negative.

Before the bubble bursting process, the mean velocities of bubbles and droplets, $\bar{u}$, decreased gradually with the increase in the distance from the discharge orifice as shown in Figure 5. When the bubble internal pressure was greater than its surface tension, the bubble would burst, as shown in Figure 7. Some film droplets formed due to the bubble bursting. The axial component velocity of the film droplets was $u^{\prime}$, as shown in Figure 7 . The direction of velocities $u^{\prime}$ was along the direction in which the bubble velocity was decreasing. The actual velocities of the film droplets were $\bar{u}+u^{\prime}$. In that manner, the droplets ejection kept a scope at the positions from $20 \mathrm{~mm}$ to $120 \mathrm{~mm}$. After $L=120 \mathrm{~mm}$, bubbles have burst as the droplets, the velocity distribution of the film droplets would decay with the increase of the axis distance at $L=140 \mathrm{~mm}$ - $180 \mathrm{~mm}$.

\subsection{SMD distribution of the swirl atomizers}

Figure 8 describes the $S M D$ radial distribution for two swirl atomizers (A and $\mathrm{B})$. The gas and liquid pressures 

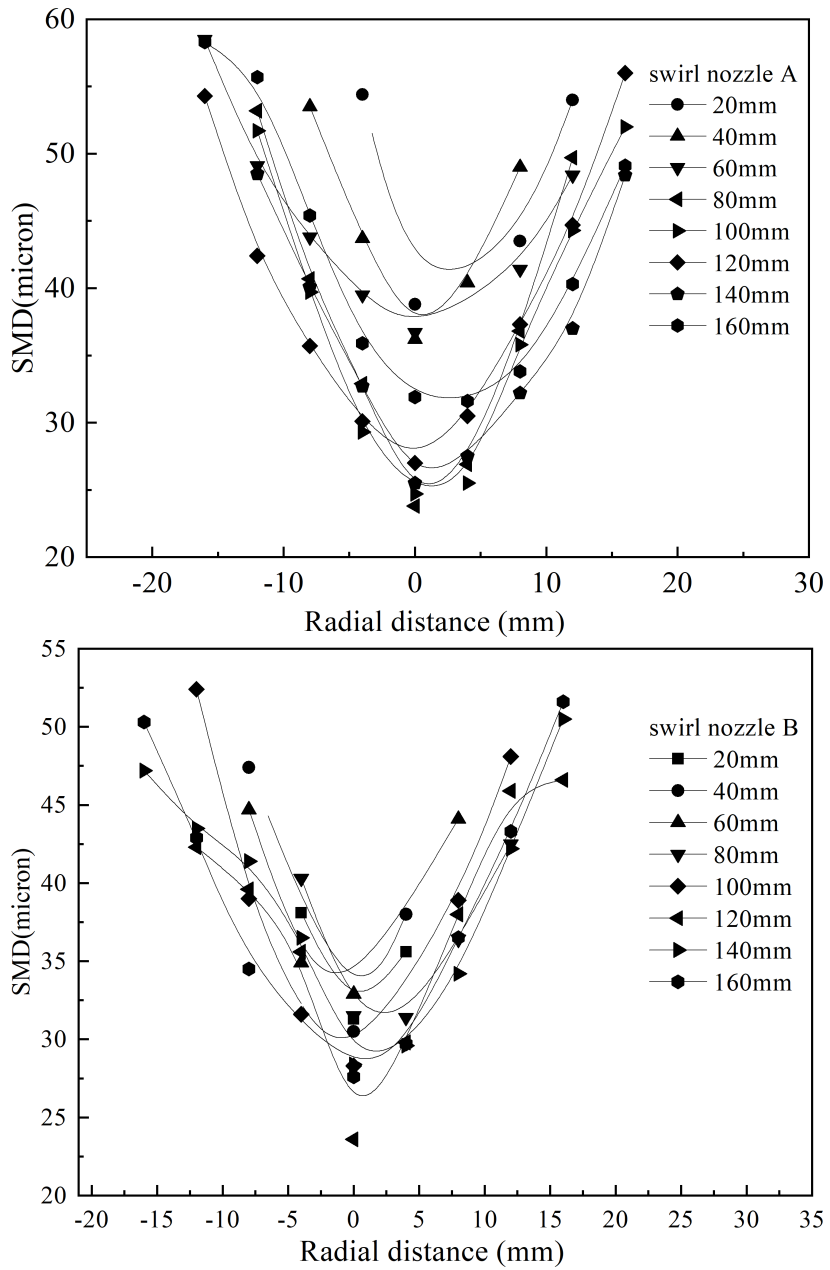

Figure 8: Velocity $U$ of swirl atomizer $B$ in radial distribution

were set to be $P_{\alpha}=0.3 \mathrm{MPa}$ ( $\alpha=1,2$ represented the liquid or gas phase, respectively.). The gas-liquid rate was set to be $G L R=0.1$. The distance from the discharge orifice was $L(L=20 \mathrm{~mm}-160 \mathrm{~mm})$.

The $S M D$ radial distributions of the droplets were symmetrical for two atomizers. The SMD of the droplets increased gradually along the radial direction, and the minimum value was obtained in the discharge orifice centre. The $S M D$ of the droplets became gradually smaller with the increase in the distance from the discharge orifice. The droplets SMD of the atomizer B was smaller than that of the atomizer A. However, the atomization angle in the swirl atomizer B was larger than that in the swirl atomizer A. In terms of physics, more bubbles were generated in the swirl atomizer $\mathrm{B}$. The bubble bursting process took place in the whole measurement process. Compared to the swirl atomizer A, the effect of the swirl atomizer B on the bubble bursting was more intense.

\section{Conclusion}

The atomization characteristic for two swirl atomizers with different configurations has been experimentally investigated in this paper. Some conclusions can be drawn from the results above:

1. When the GLR is small, the atomization is not stable, and the increase in the GLR improves the atomization process. The optimal region can be obtained.

2. The velocity and $S M D$ distributions of the droplets are symmetrical on the discharge orifice centre for both swirl atomizers.

3. The droplets velocities along the axial direction keep a scope with the increase in the distance from the discharge orifice. The effect of the atomization on the velocity and $S M D$ distributions of the droplets in the swirl atomizer $B$ are better than those in the swirl atomizer $\mathrm{A}$.

4. In the effervescent atomization process, some droplets velocities are displayed as negative.

Acknowledgement: The financial support of China National Nature Science Funds (Support No. 51806057 and 51276055), the Hebei Young Science Founds (No. E2019202460 and E2019202198), Tianjin Science and Technology project (No. 19YFZCSF00850), Key Research Program Projects of Hebei Province (No. 19274502D), Industrial Technology Research of Hebei University of Technology (No. ZBYJY201902) and Technology Research Project of Hebei Higher Education (No. QN2017050 and QN2018067) are gratefully acknowledged.

\section{References}

[1] Lefebvre A.H., Wang X.F., Martin C.A., Spray characteristics of aerated-liquid pressure atomizers, Journal of Propulsion and Power, 1988, 4, 293-298.

[2] Sovani S.D., Sojka P.E., Lefebvre A.H., Effervescent atomization, Progress in Energy and Combustion Science, 2001, 27, 483-521.

[3] Li J., Lefebvre A.H., Rollbuhler J.R., Effervescent atomizers for small gas turbines, American Society of Mechanical Engineers, 1994,94-GT-495, 1-6.

[4] Buckner H.E., Sojka P.E., Effervescent atomization of high viscosity fluids. Part 1: Newtonian liquids, Atomization Sprays, 1991, 1, 239-252.

[5] Buckner H.E., Sojka P.E., Effervescent atomization of high viscosity fluids. Part 2: non-Newtonian liquids, Atomization Sprays, 1993, 3, 157-170.

[6] Roesler T.C., Lefebvre A.H., Studies on aerated-liquid atomization, Int J Turbo Jet Engines, 1989, 6, 221-230. 
[7] Roesler T.C., Lefebvre A.H., Photographic studies on aerated liquid atomization, combustion fundamentals and applications, Proceedings of the Meeting of the Central States Section of the Combustion Institute, Indianapolis, Indiana, Paper 3, 1988.

[8] Santangelo P.J., Sojka P.E., A holographic investigation of the near nozzle structure of an effervescent atomizer produced spray, Atomization Sprays, 1995, 5, 137-155.

[9] Konstantinov D., Marsh R., Bowen P., Crayford A., Effervescent atomization for industrial energy-technology review, Atomization Sprays, 2010, 20, 525-552.

[10] Jedelsky J., Jicha M., Energy conversion during effervescent atomization, Fuel, 2013, 111, 836-844.

[11] Jedelsky J., Jicha M., Spray characteristics and liquid distribution of multi-hole effervescent atomisers for industrial burners, Applied Thermal Engineering, 2016, 96, 286-296.

[12] Marek O., Magdalena M., Sylwia W., Andżelika K., Małgorzat M., Anna G., Tomasz S., The concept design and study of twin-fluid effervescent atomizer with air stone aerator, Chemical Engineering \&Processing Intensification, 2018, 124, 24-28.

[13] Rahman M.A., Balzan M., Heidrick T., Fleck B.A., Effects of the gas phase molecular weight and bubble size on effervescent atomization, International Journal of Multiphase Flow, 2016,38, 35-52.

[14] Wang J., Li G., Zhu H., Luo J., Sundén B.. Experimental investigation on convective heat transfer of ferrofluids inside a pipe under various magnet orientations. International Journal of Heat and Mass Transfer, 2019,132, 407-419
[15] Wang X.F., Chin J.S., Lefebvre A.H., Influence of gas injector geometry on atomization performance of aerated-liquid nozzles, Int J Turbo Jet Engines, 1989, 6, 271-280.

[16] Liu C., Liu F., Yang J., Mu Y., Hu C., Xu G., Experimental investigations of spray generated by a pressure swirl atomizer, Journal of the Energy Institute, 2019,92,210-221.

[17] Jedelsky J., Maly M., Corral N., Wigley G., Janackova L., Jicha M., Air-liquid interactions in a pressure-swirl spray, International Journal of Heat and Mass Transfer, 2018,121,788-804.

[18] Ge W., Lu G., Xu X., Wang X., Droplet spreading and permeating on the hybrid-wettability porous substrates: alattice Boltzmann method study, Open Physics, 2016,14,483-491.

[19] Kourmatzis A., Lowe A., Masri A.R., Combined effervescent and airblast atomization of a liquid jet, Experimental Thermal and Fluid Science, 2016, 75, 66-76.

[20] Ma R., Dong B., Yu Z., Zhang T, Wang Y, Li W, An experimental study on the spray characteristics of the air-blast atomizer, Applied Thermal Engineering, 2015, 88, 149-156.

[21] Yang Y.,, Liu P., Zhang W., Liu Z., Sun H., Zhang L., Zhao J., Song W., Liu L., An S., Yao J., Effect of the pore size distribution on the displacement efficiency of multiphase flow in porous media, Open Physics, 2016,14, 610-616.

[22] Roesler T.C., An experimental study of aerated-liquid atomization, PhD thesis, Purdue University, 1988

[23] Squire H.B., Investigation of the instability of a moving liquid film, Brit J Appl Phys, 1953, 4, 167-169. 